\title{
An Introduction to the Special Issue from 2018's Qualitative Analysis Conference: Creating, Negotiating, and Transcending Social Boundaries in Everyday Life
}

\author{
Dawne Clarke \\ St. Thomas University, Canada
}

DOI: http://dx.doi.org/10.18778/1733-8077.16.3.01

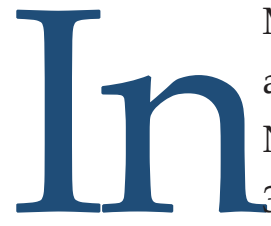

May 2018, qualitative researchers from all over the world met in Fredericton, New Brunswick to participate in the 35th annual Qualitative Analysis Conference. This conference brings together undergraduate and graduate students, novice and established researchers in an open and collegial forum to explore the intricacies of qualitative research.

Coming together under the auspices of Creating, $\mathrm{Ne}$ gotiating, and Transcending Social Boundaries in Everyday Life, participants explored boundaries as a key concept in the social science tool-kit. Boundaries are a rich site of exploration, even more so now as we find ourselves establishing and challenging

Dawne Clarke teaches in the Department of Criminology \& Criminal Justice at St. Thomas University, Fredericton, NB, Canada.

email address: dclarke@stu.ca taken-for-granted boundaries in health, political, social, and economic contexts and what they mean in a COVID-19 world. For example, in New Brunswick, there have been reported instances of "plate shaming" emerged as a practice that is a direct response to boundary "violations." Out of province travelers, visible because of their out-of-province license plates, are shamed and humiliated, even punitively sanctioned for travelling from another province or state, violating provincial and/or federal boundaries. What was once an accepted, welcomed, and encouraging practice, especially for provinces heavily-reliant on tourism, travelling is now a boundary-violation.

The three papers in this special issue appear to have little in common, however, the critical examination of boundaries in multiple social contexts speaks how boundaries shape, sustain, create, deter, prohibit all kinds of social, political, and economic facets of our everyday world. Physical, social, temporal, spatial, virtual, and relational; boundaries provide a critical analysis space to examine the everyday world. At the other end of the spectrum is transcending those boundaries. 
This allows the exploration of new and emerging spaces deepening our understanding of boundaries as various shades of gray. Consider again plate shaming; we cannot assume the boundary violation is just that of the driver wanting access to the province. That boundary is maintained, or not, at the discretion of peace officers stationed at the border. How does discretionary authority reinforce or violate those state-sanctioned boundaries?

The following papers challenge boundary-making activities in a variety of contexts. To begin, we enter a world where the boundaries of what it means to be human are questioned. Exploring Other-Than-Human Identity: A Narrative Approach to Otherkin, Therianthropes, and Vampires, by Clive Baldwin and Lauren Ripley, explores transgressing identity boundaries by investigating and acknowledging the gray-area boundaries between human and non-human. Interviews with Otherkin, people with marginal, concealable identities who believe themselves to be something other than human; dragons, vampires, werewolves or other creatures not-of-this-world, or non-biological entities like androids, and Therians, people who identify in varying degrees as other-than-humans; dogs, wolves, dolphins, bears, cats, et cetera. Otherkin and Therians, then, illustrate human-non-human boundary transgression at the most basic level, our sense of self. Exploring the reshaping of identity boundaries creates an opening to understand a community who engage in constant boundary negotiations in a social world characterized by marginalization.
Stella Čapek's paper, Trees as Dialogue: Negotiating Boundaries with the Anne Frank Sapling Project, asks us to consider how a small tree sapling grafted from the chestnut tree that stood outside of Anne Frank's attic window while she wrote her famous diary can link the tree to dialogue about past and present social justice issues. The sapling, installed at the Clinton Presidential Center in Little Rock, Arkansas, acquires meaning as a "significant other" and crosses social, political, historical, and social justice boundaries, reinforcing social science commitment to challenging the taken-for-granted understandings of the social world, in this case, a tree is so much more than a tree and it can transcend boundaries, creating a bridge between the past and the present.

Finally, Lynne Gouliquer, Carmen Poulin, and Jennifer McWilliams question the othering of female firefighters and how they transcend multiple taken-for-granted boundaries relating to gender, physicality, sexual orientation, ethnicity, age. Othering manifests in discrimination, hostile work environments, and undermining of firefighter identity as women continue to push forward in a traditionally male-dominated occupation.

Each of the above papers represents the quality of empirical investigation and analysis that serves as the hallmark of the Qualitative Analysis Conference. While the 2020 Qualitative Conference was postponed by COVID-19, plans for the Qualitatives 2021, at Brescia College in London, Ontario, are underway. Details can be found at www.qualitatives.ca, and I hope you will consider submitting an abstract and/or attending.

\section{Citation}

Clarke, Dawne. 2020. “An Introduction to the Special Issue from 2018's Qualitative Analysis Conference: Creating, Negotiating, and Transcending Social Boundaries in Everyday Life." Qualitative Sociology Review 16(3):6-7. Retrieved Month, Year (http://www. qualitativesociologyreview.org/ENG/archive_eng.php). DOI: http://dx.doi.org/10.18778/1733-8077.16.3.01 